This was shown experimentally by Gustav Mann more than forty years ago. The converse is also true, and the brain worker who engages in strenuous exercise at the week-end is thereby sapping his stores of mental energy.

Another matter discussed in the report relates to the employment of children and young persons. Here it is important to realize the strain which conditions of work and environment may throw upon the adolescent.

Next the report treats of the promotion of health and welfare. The important subjects of adequate nutrition and well-cooked food are considered, mess-rooms, canteens and communal feeding centres are reviewed, billeting of workers and ventilation and lighting during the black-out are discussed. A series of practical recommendations on all these matters closes the report.

Even as the report appears, new measures have been taken by the Ministry of Labour and National Service to promote industrial welfare. There is a scheme to cut down working time to 55 or 56 hours a week, factory inspectors have been instructed to enforce the Factories' Act in the care of women and young persons and an Order has been made by the Minister requiring the occupier of any named factory to make arrangements for parttime or whole-time medical men, nurses and officers to supervise the welfare of the persons employed. The necessity will be determined by the number of workers employed in a given factory or by special conditions such as dangerous processes or isolated position in a factory. Already some three hundred medical men and women-fifty of them in a whole-time capacity-are attached to factories and business organizations in Great Britain and there is a responsible Association of Industrial Medical Officers.

The position created by this Order is of great importance. It is State recognition of preventive medicine as a function of works management, and the extended application of the results of scientific and medical research for the benefit of the industrial workers should make a substantial contribution to national health. The Order is a beginning, but it has great possibilities. It must be remembered that workers spend only a portion of their lives in the factory, and that to safeguard their health and efficiency preventive medicine must take account of their social environment. In other words, industrial hygiene must not work in water-tight compartments but must be closely co-ordinated with the national health services provided by local authorities and the national health insurance service, all working under the auspices of the Ministry of Health. Otherwise there will be waste of effort, overlapping and duplication of health services and unnecessary expenditure.

\title{
TEACHING OF ECONOMIC BIOLOGY
}

$\mathrm{T}^{\mathrm{T}}$ HE intensification of the present conflict has brought with it many problems and none more poignant than its effects upon children. To a developing child the significance of the War is often either resolved into a singular, fervent and intense hatred of the Nazi machine that has so considerably inconvenienced its peculiar world or, very frequently with adolescent children, a confusion of ideas that leaves them groping for a clearer understanding of the deeper issues involved. The traditional and time-honoured British policy of abandoning political factions at the school portals is an admirable one that shows no sign of being relaxed despite the bitterness and mendacity of enemy propaganda. Economic factors, however, have become so paramount in importance that with daily Press references to the blockade, the repeated aerial attacks on merchant shipping and the civilian population, and the ruthlessness of the inhuman submarine warfare, their effects upon the child mind cannot be ignored. On these and related topics, further assistance from their teachers is constantly demanded by ardent youthful inquirers.

The opportunities presented here to the geography and domestic science teachers are manifold and clear. The co-operation of other teachers in illustrating this economic picture is not so frequently invoked nor even envisaged. Yet the role of the mathematics or science teachers is none the less essential in presenting a composite picture of the interlacing economic network. The biology teacher, particularly, is able to play an effective part in relating descriptions of essential commodities to their natural economy and source of origin. In times of peace, the teaching of economic biology has been adopted in surprisingly few schools in Great Britain, although in those 
schools where such instruction has been given its introduction has been acclaimed as a definite acquisition to the more realistic nature of the curriculum. In war also a greater extension of the teaching of some of the economic aspects of biology would be of inestimable value in facilitating the adjustment of individual to the changing needs of our rapidly evolving society.

The argument for the teaching of applied biology with reference to the economic needs no flogging. It would serve to quicken the interest of the pupil in articles that he is constantly seeing. It should enable him to become more familiar with the interwoven relationships between all living organisms. Latex and rubber, leather, spices and condiments, perfumes, tobacco, dyestuffs, beverages, soap and drugs could all be described in relation to their natural economy as also could certain bacteria, particularly those which are helpful to man like cheese-ripeners, tobacco-maturers, etc. References to the constantly changing methods by means of which man is making greater economic use of plants and animals should do much towards helping the child to appreciate the uniqueness of man as a successful exploiter and utilizer of many different aspects of his environment, in contrast to the circumscribed range of other living organisms. The presentation of these and related topics in a historical setting affords wide scope for the building up of attitudes which would in part enable a child to appreciate the dynamics of social change.

The present restrictions in consumption of certain food products offer special opportunities to the adaptable teacher. Rationing of staple commodities like tea, sugar, butter, and bacon could be made the basis of lessons on the place of these foodstuffs in general nutrition and economy. These might be linked up with the campaign being carried out by the Ministry of Feod, which could be made use of in emphasizing the fact that suggested substitutes are not necessarily inferior in food value to articles which have been accepted as almost a part of the national heritage. (The word Ersatz has been partly instrumental in creating the impression that substitute foods are of lower nutritional standard than the ones they are designed to replace.) In conjunction with the geography specialists, other lessons could be used to describe the source of origin, methods of production and distribution of necessary food-stuffs, articles of clothing, footwear, etc.
Descriptions of the transport of food products like meat, fruit and fish would scarcely be complete without reference to the various methods of conditioning and preservation. Drying, smoking, salting, canning and other processes which alter the appearance and taste of the food product could be considered with reference to food substances that frequently form a part of the dietary of the child. Lessons on dried figs, bacon and ham, kippers and bloaters, fruit, vegetable and fish canning, etc., would be particularly effective in emphasizing the unique place of man as an unraveller of the-to him-tangled skeins of Nature and as one who has learned to mould her pattern to his own design. The preservation of foods in their more or less natural state by the more recently developed cold-storage devices would also form an invaluable introduction to an account of the growing interdependence of the various components of the British Empire.

The limitations of ice as a natural preservative -although the caviare taken to ancient Egypt embedded in the snow of the Caucasus apparently had lost little of its appeal to the recipients-and the introduction of machinery to produce cold artificially could be used to show how, some fifty years ago, mechanical refrigeration was first applied to the storage of food. The growing scarcity of meat in Great Britain in the seventies of the last century, due largely to the rise of industrialism, coupled with the urgent need to find a profitable outlet for the large quantities of food materials in the producing countries like Australia, New Zealand and South America, could demonstrate how the economic problems led to the first attempts at installing refrigerating machinery in ships to bring frozen meat from overseas. The necessity of refrigeration assumes added importance to-day with the diversion of merchant ships from their customary trade-routes.

The excellent series of posters now widely distributed throughout the country in which attention is directed to the raw materials produced by various parts of the British Empire would be useful starting points in lessons that would foster a better understanding of the vital inter-relations between Dominions, Colonies, Dependencies and the mother country.

In teaching children about articles they eat and drink and in which they clothe themselves, a valu. able link is made in introducing them to a wider appreciation of the lives lived by other people in different climatic regions. The absolute necessity 
of the reindeer to Laplanders as a provider of food, clothing, utensils and fuel, and the complete dependence of natives of Papua upon shellfish and yams are examples of how the story of civilization might be re-lived in the classroom.

Greater attention might also profitably be paid to the economic aspects of biological control. The late Mr. Frederick Muir's estimation that the introduction of the Tachinid parasite of the weevil borer of sugar cane into the Hawaiian Islands saved the cane growers about one million pounds a year is a spectacular example of the inscriptions that might be given to illustrate the potentialities of control of pests by biological methods. This could be adequately supplemented by discussions more prosaic, but none the less important and effective, of the methods of control which have been originated and which are being constantly extended at the Laboratory of the Imperial Institute of Entomology at Farnham Royal. The value of the film in augmenting the learning process by providing visual experiences beyond the concept of words springs readily to mind in considering this issue. An outstanding film on prickly pear control produced by Australia Trade Publicity would be invaluable in presenting a picture of man's ceaseless fight against natural forces in his march towards civilization.

The remarkable plagues of insects which occur from time to time, as instanced by the appearance of flying ants in amazing numbers in the streets of Croydon recently, and other cyclical fluctuations of animal populations would be useful in bringing out the importance of the effects of the alternate abundance and scarcity of organisms upon which human life is dependent. Price variations, together with the need for investigating the causes of scarcity and the introduction of corrective and ameliorative methods, could be considered in connexion with lessons on the fickleness of Nature in providing a dearth of life-giving crops interspersed. with seasons of plenteous bounty.

The introduction of a more liberal use of economic biology in the school syllabus would have a further advantage in dispelling the unfortunately too prevalent belief that practical biological experiments and demonstrations can only be taught by using stock equipment and apparatus which are usually of an expensive type. Discussion of topics concerning articles that form part of our everyday habitat could be illustrated quite adequately by practical observations making use of the articles themselves. The question often debated as to whether the teaching of science should either focus upon the inculcation of mental discipline or should play a more considerable part in introducing the student to the wider human and social aspects of science need scarcely arise in a course centred round economic products. Formal training could be given using the commodity under consideration as experimental material, while the human implications would inevitably be developed both in the classroom itself and by visits to local museums, botanic gardens and, where possible, to shops and stores which often display models and exhibitions depicting the derivation of their products from the raw materials. It might be argued by reactionary observers that this type of teaching would introduce too much of the utilitarian aspects of science and might even approximate towards totalitarian methods of imparting information. Further reflection, however, would show that this tendency is scarcely likely to develop even with those enthusiasts who are considered to be extremists in their method of propounding a more everyday outlook in their science teaching. Where knowledge is freely administered and where information is never withheld there also is the mainspring of freedom of thought ; and where the imparted information is made to link up with the problems of daily life, there, also, must be a better understanding and a more resolute confronting of our own difficulties and, equally important, those of our neighbours in other lands.

For the previous neglect in schools of the teaching of biological questions verging upon the economic, the universities must be held responsible in great part. The recruit to the school teaching profession attempts little during his first years except a repetition of factual material that he has assiduously collected in his Alma Mater. Although there are notable exceptions, in many of the universities little or no instruction is provided in economic biology even for students of honours degree standard. It is almost inevitable that this deficiency in the equipment of potential teachers must have an adverse effect upon the liberality of their early teaching at least. Even for students who are not contemplating entry to the teaching profession, the introduction of lecture courses and practical demonstrations relating to economic products would add both to the attractiveness of the syllabus and the usefulness of their training as a preparation for the rigours of modern life. 